\title{
PERSEPSI MASYARAKAT TERHADAP PENDIDIKAN ANAK YATIM DI KECAMATAN BALUSU KABUPATEN BARRU
}

\author{
Herwin ${ }^{1}$, Kaharuddin $^{2}$, Lukman Ismail ${ }^{3}$ \\ ${ }^{1}$ Pendidikan Sosiologi, Universitas Muhammadiyah Makassar \\ Email: herwin131k@gmail.ac.id \\ ${ }^{2}$ Pendidikan Sosiologi, Universitas Muhammadiyah Makassar \\ Email: kaharuddin@unismuh.ac.id \\ ${ }^{3}$ Pendidikan Sosiologi, Universitas Muhammadiyah Makassar \\ Email: lukmanismail@unismuh.ac.id
}

\begin{abstract}
This study examines about Society's Perceptions Toward the Education of Orphaned Children at Balusu District in Barru Regency. The problem that riview in this thesis are: (i) to know the interactions of society with orphaned children at Balusu district in Barru regency. (ii) to know society's perceptions toward the education of orphaned children at Balusu district in Barru regency. Type of the research that use was descriptive qualitative research that aimed to understand of society's perceptions toward the education of orphaned children at Balusu district in Barru regency. The informant was determined by purposive sampling based on the characteristic of the informant that was set that is the profession of society as an employee and businessman.

The type of this research was descriptive qualitative research, including the systematic activity to got the answer toward the problem that submitted. Qualitative research is a method or the way of systematic research that used for review or investigate an object in the scientific background without manipulation and without hypothesis testing, natural methods when the result of research that expected not generalization based on the standard of quantity, however the meaning (quantity side) and the phenomenon that observed.

The result of this research show that, society perceptions toward education of the orphaned children, by education can improve the ability, form a character and the civilized nation with dignity in order to educate the of the nation, aimed to develop the potential of students to become people of faith and piety to Allah Swt, noble, healthy, knowledgeable, creative, independent, and be a democratic and responsibility people.
\end{abstract}

Keywords : Society and Education orphaned children.

Abstrak. Penelitian ini mengkaji tentang Persepsi Masyarakat Terhadap Pendidikan Anak Yatim Di Kecamatan Balusu Kabupaten Barru. Masalah yang dikaji dalam skripsi ini adalah: (i) Untuk mengetahui interkasi Masyarakat dengan anak yatim di kecamatan balusu kabupaten barru., (ii) Untuk mengetahui persepsi Masyarakat terhadap pendidikan Anak Yatim di kecamatan balusu kabupaten barru. Jenis penelitian yang di lakukan adalah jenis penelitian kualitatif deskriptif yang bertujuan memahami persepsi Masyarakat terhadap pendidikan anak yatim di kecamatan balusu kabupaten barru. Informan di tentukan secara purposive sampling berdasarkan karakteristikinforman yang telah di tetapkan yaitu masyarakat yang berprofesi sebagai pegawai dan pengusaha.

Jenis penelitian ini adalah penelitian kualitatif deskriptif, meliputi kegiatan yang sistematik untuk mendapatkan jawaban atas permasalahan yang di ajukan. Penelitian kualitatif adalah metode atau jalan penelitian yang sistematis yang di gunakan untuk mengkaji atau meneliti suatu objek pada latar alamiah tanpa ada manupulasi di dalamnya tanpa ada pengujian hipotesis, metode-metode yang alamiah ketika hasil penelitian yang di harapkan bukanlah generalisasi berdasarkan ukuran-ukuran kuantitas, namun makna (segi kualitas) dan fenomena yang diamati. 
Hasil penelitian menunjukkan bahwa, persepsi Masyarakat terhadap pendidikan Anak yatim, dengan adanya pendidikan dapat mengembangkan kemampuan dan membentuk watak serta peradaban bangsa yang bermartabat dalam rangka mencerdaskan kehidupan bangsa, bertujuan untuk berkembangnya potensi peserta didik agar menjadi manusia yang beriman dan bertakwa kepada Allahh swt, berakhlak mulia, sehat, berilmu, kreatif, mandiri dan menjadi warga negara yang demokratis serta bertanggung jawab.

Kata kunci : Masyarakat dan Pendidikan Anak Yatim

\section{PENDAHULUAN}

Pendidikan sebagai pilar utama peningkatan kualitas sumber daya manusia. Pendidikan bermutu salah satu langkah utama dalam upaya meningkatkan kesejahteraan dan taraf hidup manusia. Dengan kata lain, pendidikan mampu mengatasi masalah kemiskinan dan masalah lain yang menyertainya. Mengingat pentingnya pendidikan bagi kehidupan, pemerintah kita selalu melakukan upaya peningkatan dalam bidang pendidikan. Berbagai macam langkah yang dilakukan oleh pemerintah, seperti menyediakan sarana pendidikan dengan membangun sekolah-sekolah, memberikan bantuan berupa pengadaan buku pelajaran secara gratis, memberikan dana pendidikan.

Pendidikan berkenan dengan perkembangan dan perubahan pada anak yatim, Pendidikan adalah proses mengajar dan belajar terhadap pola kelakuan manusia menurut apa yang di harapkan oleh anak yatim. tentunya pendidikan merupakan faktor yang sangat penting terhadap anak yatim dalam kelangsungan hidupnya, hal ini jelas bahwa pendidikan tidak bisa lepas begitu saja terhadap hubunganya dengan anak yatim. Tiap Masyarakat meneruskan kebudayaanya dengan beberapa perubahan kepada anak yatim melalui pendidikan, melalui interaksi dengan demikian pendidikan dapat di artikan sebagai sosialisasi. Kegiatan yang di lakukan anak yatim seperti interaksi terhadap sosialnya, merupakan perilaku utama bagi pembangunan, sehingga di perlukan kualitas (sumber daya manusia) atau SDM yang berkualitas dan memiliki potensi yang dapat diharapkan, sehingga anak yatim dapat bergerak pada arah pembangunan untuk menuju cita-cita rakyat Indonesia, yaitu bangsa yang makmur dan berkepribadian luhur. Terlebih lagi pada zaman yang semakin menuntut manusia untuk lebih dapat bersaing di era globalisasi maupun yang akan datang. Artinya, anak yatim di tuntut untuk mempunyai keterampilan atau kopotensi dalam dirinya menjadi manusia yang berguna baik bagi dirinya sendiri maupun orang lain.

Untuk mengali potensi yang di miliki oleh anak yatim maka di perlukan pendidikan. Pendidikan merupakan suatu usaha yang dilakukan secara sadar untuk mengembangkan kemampuan yang dimiliki seseorang agar mampu menyesuaikan diri dengan lingkungannya. Dalam pendidikan diberikan tempat terjadinya proses pemberian pengalaman atau pengembangan pengalaman yang dimiliki oleh individu dengan tujuan untuk memanusiakan manusia (Wahyudin, 2007).

Di dalam Undang-Undang Dasar 1945 pasal 31 ayat 1 dan 2 ditegaskan bahwa "Tiap-tiap warga negara berhak mendapatkan pengajaran" dan "Pemerintah mengusahakan dan menyelenggarakan satu sistem pengajaran nasional, yang diatur dengan undang-undang". Sedangkan di dalam Garis-garis Besar Haluan Negara (Ketetapan Majelis Permusyawaratan Rakyat Republik Indonesia Nomor: IV/MPR/1978) dinyatakan bahwa "pendidikan berlangsung seumur hidup dan dilaksanakan di dalam lingkungan keluarga, sekolah dan masyarakat. karena itu pendidikan merupakan tanggung jawab bersama antara keluarga, masyarakat dan pemerintah Pendidikan nasional berfungsi mengembangkan kemampuan dan membentuk watak serta peradaban bangsa yang bermartabat dalam rangka mencerdaskan kehidupan bangsa, bertujuan untuk berkembangnya potensi peserta didik agar menjadi manusia yang beriman dan bertakwa kepada Allahh swt, berakhlak mulia, sehat, berilmu, kreatif, mandiri dan menjadi warga negara yang demokratis serta bertanggung jawab.

Tingkat pendidikan dalam suatu daera sebenarnya di tentukan dari bentuk daera atau perkotaan persebut. Dimana bentuk daera mencangkup tentang pola, pengaturan atau organisasi dan tata letak pemukiman yang berbeda dari satu daera ke daera lain. Oleh karenanya bentuk perkotaan sangat berpengaruh atau menentukan tingkat perkembangan pendidikan. Sering pula 
suatu bentuk perkotaan berkaitan erat dengan karakteristik social yang dominan pada daera tersebut. Sehingga kebutuhan vital, tingkat pengetahuan, dan tingkat teknologi yang dimiliki para kota sering berperang dalam membentuk dan menetukan tata letak (ruang) suatu kota.

Secara material sebagian besar Masyarakat dan pendesaan setuju bahwa pendidikan sangat penting bagi anak yatim, karena dengan pendidikan dapat memberi wawasan yang luas dan mencerdaskan. Di samping itu pendidikan merupakan dasar paling utama untuk mencapai kesuksesan dan juga dengan bekal adanya pendidikan kita menjadi orang yang terpandang karena wawasan yang luas. tanpa pendidikan manusia tidak dapat menyusaikan dengan kebutuhan masyarakat dan lingkunganya.Cara pandang inilah yang dapat diartikan sebagai persepsi. Sehingga bentuk persepsi ini masyarakat kota harus keutamaan menyantuni Anak Yatim.

\section{METODE PENELITIAN}

Jenis penelitian yang digunakan oleh peneliti adalah penelitian kualitatif deskriptif. Kualitatif adalah penelitian yang bermaksud untuk memenuhi fenomena tentang yang dialami subjek peneliti. Deskriptif adalah berupa kata-kata, dan gambar. Penelitian kualitatif deskriptif digunakan untuk menguraikan fakta mengenai Persepsi Masyarakat Terhadap Pendidikan Anak Yatim Di Kecamatan Balusu Kabupaten Barru. Keadaan dan situasi yang akan digambarkan dalam penelitian ini adalah bagaimana Persepsi Masyarakat Terhadap Pendidikan Anak Yatim Di Kecamatan Balusu Kabupaten Barru Metode deskriptif ini ialah menafsirkan data yang ada, misalnya tentang situasi yang dialami, suatu hubungan, suatu proses yang sedang berlangsung, kelainan yang sedang muncul, kecenderungan yang nampak pertentangan yang meruncing, dan sebagainya. Tujuan utama penelitian kualitatif adalah untuk memahami fenomena atau gejala sosial yang terjadi di masyarakat.

\section{HASIL DAN PEMBAHASAN}

Setelah melakukan observasi,dokumentasi,partisipatif,dan angket di lapangan maka akan di sajikan data-data yang di peroleh dari penelitian. Untuk lebih jelasnya dapat di lihat sabagai berikut :

\section{Interaksi Masyarakat Terhadap Anak Yatim Di Kecamatan Balusu Kabupaten Barru.}

Salah satu interaksi sosial dapat terjalin dengan baik jika dalam suatu hubungan terdapat dua individu atau lebih, dimana kelakuan individu yang satu mempengaruhi, mengubah, atau memperbaiki kelakuan individu yang lain atau sebaliknya sehingga dapat terjalin kerjasama yang baik di antara para pelaku interaksi sosial. Seseorang tentunya akan mengadakan hubungan atau interaksi dengan orang lain dalam kehidupan sehari-hari.

Interaksi sosial adalah hubungan antara individu dengan individu, kelompok dengan individu maupun kelompok dengan kelompok. Interaksi sosial antar Masyarakat dengan Anak Yatim terlihat dengan obrolan mereka ketika sedang ada sosialisasi. Hal ini biasa dijumpai di salah satu pusat di kecamatan balusu yang sering ditempati para masyarakat tinggal.

Interaksi yang terjadi antara masyarakat dengan Anak yatim terbagi menjadi dua bentuk, yaitu interaksi sosial asosiatif dan disosiatif.

\section{1) Pola interaksi asosiatif}

Proses asosiatif adalah sebuah proses yang terjadi saling pengertian dan kerja sama timbal balik antara orang per orang atau kelompok satu dengan lainnya, di mana proses ini menghasilkan pencapaian tujuantujuan bersama. (Bungin, 2011: 58).

\section{a. Kerja sama (cooperation)}

Suatu usaha bersama antara orang perorangan atau kelompok manusia untuk mencapai suatu atau beberapa tujuan bersama. Bentuk kerja sama tersebut berkembang apabila orang dapat digerakan untuk mencapai suatu 
tujuan bersama dan harus ada kesadaran bahwa tujuan tersebut di kemudian hari mempunyai manfaat bagi semua. Juga harus ada iklim yang menyenangkan dalam pembagian kerja serta balas jasa yang akan diterima.

Dalam perkembangan selanjutnya, keahlian-keahlian tertentu diperlukan bagi mereka yang bekerja sama supaya rencana kerja samanya dapat terlaksana dengan baik. Kerja sama timbul karena orientasi orang-perorangan terhadap kelompoknya (yaitu in-group-nya) dan kelompok lainnya (yang merupakan out-groupnya). Kerja sama akan bertambah kuat jika ada hal-hal yang menyinggung anggota/perorangan lainnya.

Interaksi Masyarakat merupakan salah satu bentuk sosialisasi antara masyarakat khususnya Anak Yatim yang ada di daerah kecamatan balusu kabupaten barru yang memberikan pengaruh yang besar.

Pada hakikatnya, faktor lingkungan sangat berperan dalam mendukung pembetukan akhlak Anak, yang akan Nampak setelah anak meningkat umur ke jenjang kedewasaan interaksi social yang wajar antara anak dengan anggota-anggota masyarakat nilai-nilai perilaku, norma-norma agama dan sosial merupakan peraturan yang harus di patuhi oleh setiap induvidu yang ada dalam kelompok. Perkembangan sosial merupakan pencapaian kematangan dalam hubungan sosial. Dapat juga di katakan sebagai proses belajar untuk menyusaikan diri terhadap norma-norma kelompok, Moral dan tradisi, dalam dunia pendidikan, pembinaan akhlak dititikberatkan pada pembentukan perilaku agar anak tidak mengalami penyimpangan. Dengan demikian, anak tidak mengalami" Juvenile Deliquency" yang berarti kenakalan anak. Sebab dalam pembinaan perilaku di tekankan bahwa anak di tuntut untuk belajar memiliki rasa tanggung jawab. Bukan saja menjadi tanggung jawab pemerintah,melainkan tanggung jawab seluruh rakyat Indonesia. Hal ini berarti bahwa pembangunan pendidikan nasional tidak hanya mengejar kemapuan lahirlah semata-mata tetapi butuh kesalarasan dan keseimbangan. Dengan demikian undang-undang ini jelas bahwa pemerintah pusat mengingatkan segala bentuk program nasional bisa di berdasarkan oleh setiap masyarakat di daerah-daerah. Berikut hasil wawancara dengan Masyarakat khususnya kelurahan Takkalasi.

\section{b. Akomodasi (Accomodation)}

Pengertian Istilah Akomodasi dipergunakan dalam dua arti: menujuk pada suatu keadaan dan untuk menunjuk pada suatu proses. Akomodasi menunjuk pada keadaan, adanya suatu keseimbangan dalam interaksi antara orang-perorangan atau kelompok-kelompok manusia dalam kaitannya dengan norma-norma sosial dan nilai-nilai sosial yang berlaku dalam masyarakat. Sebagai suatu proses akomodasi menunjuk pada usaha-usaha manusia untuk meredakan suatu pertentangan yaitu usaha-usaha manusia untuk mencapai kestabilan. Menurut Gillin dan Gillin dalam soekanto (2006: 310) akomodasi adalah suatu perngertian yang digunakan oleh para sosiolog untuk menggambarkan suatu proses dalam hubungan-hubungan sosial yang sama artinya dengan adaptasi dalam biologi.

Hasil observasi peneliti dalam bentuk akomodasi yang terjadi antara masyarakat terhadap Anak Yatim yaitu dilihat dari bagaimana masyarakat mampu berbaur secara cepat dengan Anak Yatim yang memiliki cara tersendiri dalam proses memahami kaidah-kaidah.

\section{Persepsi Masyarakat Terhadap Pendidikan Anak Yatim di Kecamatan Balusu Kabupaten Barru}

Pentingnya pendidikan merupakan sebagai pilar utama peningkatan kualitas sumber daya manusia dan mengembangkan kemampuan dan membentuk watak serta peradaban bangsa yang bermartabat dalam rangka mencerdaskan kehidupan bangsa, bertujuan untuk berkembangnya potensi peserta didik agar menjadi manusia yang beriman dan bertakwa kepada Allah SWT, berakhlak mulia, sehat, berilmu, kreatif, mandiri dan menjadi warga negara yang demokratis serta bertanggung jawab. 
Partisipasi masyarakat sering dianggap sebagai bagian yang tidak terlepas dalam upaya sosialisasi antara anak yatim dan tidak dapat terlepas dari peran serta masyarakat. Masyarakat perlu aktif berpartisipasi dan dilibatkan dalam pendidikan anak yatim, sehingga mampu mengembangkan dayanya secara kreatif serta memiliki kesadaran kritis. Partisipasi masyarakat peduli dengan pendidikan anak yatim adalah kerjasama rakyat dan pemerintah dalam merencanakan, melaksanakan, dan membantu anak yatim seperti halnya memeberikan bantuan seperti sumbangan pada panti asuhan atau jadi donator tetap. Kerjasama ini menuntut hubungan yang setara antara rakyat dan pemerintah. Oleh karena itu, upaya perlu dilakukan agar rakyat memiliki kapasitas baik secara individu maupun kelembagaan dalam menunjang keberhasilan. Berdasarkan kategori persepsi terhadap peran Masyarakat salah satu kontak yang berjalin antara hubungan masyarakat dan anak yatim. munkin kedua perilaku itu di picu oleh variable. Kepedulian masyarakat akan pentinya pendidikan bagi anak yatim sangat baik. Masyarakat sadar bahwa pendidikan berdampak pada konstribusi masyarakat ketika di hadapkan pada permasalahanpermasalahan yang ada di masyarakat.

Secara umum, persepsi para partisipan tentang perang Masyarakat pada anak yatim cenderung positif bahkan tidak di temukan persepsi yang negatif. Persepsi yang muncul tentang masyarakat pada anak yatim ini adalah suatu proses kognitif yang kompleks bagaimana masyarakat peduli pada pendidikan bagi anak yatim dengan memberikan dorongan agar anak yatim betul-betul memanfaatkan pendidikan gratis yang ada di panti Asuhan, karena pendidikan dapat mengubah psikologi anak yatim. kepedulian masyarakat pada anak yatim seperti Memeluk dan mencium anak yatim dan memeberikan sumbangan kepada anak yatim dan menjadi donatur tetap. Partisipasi masyarakat sering dianggap sebagai bagian yang tidak terlepas dalam upaya sosialisasi antara anak yatim dan tidak dapat terlepas dari peran serta masyarakat. Masyarakat perlu aktif berpartisipasi dan dilibatkan dalam pendidikan anak yatim, sehingga mampu mengembangkan dayanya secara kreatif serta memiliki kesadaran kritis. Partisipasi masyarakat peduli dengan pendidikan anak yatim adalah kerjasama rakyat dan pemerintah dalam merencanakan, melaksanakan, dan membantu anak yatim seperti halnya memeberikan bantuan seperti sumbangan pada panti asuhan atau jadi donator tetap. Kerjasama ini menuntut hubungan yang setara antara rakyat dan pemerintah. Oleh karena itu, upaya perlu dilakukan agar rakyat memiliki kapasitas baik secara individu maupun kelembagaan dalam menunjang keberhasilan.

Mendidik anak yatim merupakan kewajiban orang tua mulai kecil anak haruslah sudah di kenalkan dengan segala hal yang berhubungan dengan jalan menuju arak kebaikan, karena pada dasarnya manusia terlahir dalam keadaan suci, dan orang tualah yang menjadikan ia nasrani atau majusi. Begitu juga para Masyarakat agar peduli pada anak yatim dan mengangap anak yatim sebagai anaknya, menjadikan anak yatim memiliki pendidikan yang tinggi agar kelak dalam kehidupanya lebih sejarah, maka di perlukan persepsi tentang pendidikan tinggi yang memberi makna kuat bagi anak.

\section{KESIMPULAN}

Setelah melakukan penelitian, melalui observasi dan wawancara, maka dapat di Tarik sebuah kesimpulan sebagai jawaban dari rumusan masalah yang di angkat dalam penelitian ini, kesimpulan yang dapat di Tarik.

1. Interaksi masyarakat dengan anak yatim sangat erat karena masyarakat peduli terhadap anak yatim. Proses interaksi tersebut masyarakat memberikan motivasi terhadap anak yatim mengenai pendidikan baik interaksi secara langsung maupun tidak langsung. Kita ketahui bahwa anak yatim merupakan anak yang sudah meninggal orang tuanya pasti hidupnya terguncang.

2. Persepsi Masyarakat di kecamatan balusu kabupaten barru terhadap pendidikan Anak yatim. Pendidikan sangat penting di kalangan masyarakat khususnya pendidikan bagi anak yatim 
karena dapat mendukung kesejatraan mereka di masa depan tapi hal ini juga harus di dukung oleh kemampuang mereka dalam hal kualitas pengetahuan. Dengan adanya pendidikan dapat membentuk psikologi karakter anak yatim dan menambah ilmu pengetahuan.

\section{DAFTAR PUSTAKA}

Bungin, Burhan. (2001). Metodologi Penelitian Sosial: Format-format Kuantitatif dan Kualitatif. Surabaya: Airlangga University Press.

Creswell, W Jhon. (2016). Research Design, Pendekatan Metode Kuantitafi, Kualitatif dan Campuran. Yokyakarta: Pustaka Belajar.

Damsar, Indrayani. (2017). Pengantar Sosiologi Perkotaan. Jakarta : Prenadamedia Group.

Dalyono (2007). Psikologi Pendidikan. Jakarta: PT Rineka Cipta

Idi Abdulla, Safarina HD. (2016). Sosiologi Pendidikan Induvidu, Masyarakat, dan Pendidikan. Jakarta : PT Raja Grafindo Persada

Nurhayati.(2013). https://pakarkomunikasi.com dalam interaksi sosial/(online). (diakses 5 Agustus 2019)

Nurhayati.(2013). https://pakarkomunikasi.com dalam interaksi sosial/(online). (diakses 5 Agustus 2019)

Emzir. (2011). Metodologi Penulisan Kualitatif Analisis Data. Jakarta: Raja Grafindo Persada.

Hardjo, Mudya. (2002). Filsafat Ilmu Pendidikan. Bandung : PT Remaja Rosdakarya

Hendarsono. (2005). Metode Penelitian Sosial. Yogyakarta:Liberty

Hasbulla. (2013). Dasar-Dasar Ilmu Pendidikan. Jakarta : PT Raja Grafindo Persada

Hasto Tri Djatmiko. (2008) “ Persepsi Masyarakat Perkotaan Terhadap Hutan Kota (Studi Kasus Di Rw.013, Rw.002 Dan Rw.020 Kelurahan Kayuringin Jaya, Kecamatan Bekasi Selatan, Kota Bekasi)" Institut Pertanian Bogor.

Kartono, K, dan Gulo, D. (2001). Kamus Psikologi. Bandung: CV. Pionir Jaya.

Mead, George Herbert (2008), Komunikasi Antar Pribadi, Bandung: PT Remaja Rosda Karya.

Miftahun Ni'mah Suseno, (2013). Efektifitas pembentukan karakter spritural untuk meningkatkan optimisme terhadap masa depan Anak Yatim. Universitas islam negeri sunan kalijaga Yogyakarta

Nursalam, Suardi, Syarifuddin. (2016). Teori Sosiologi Klasik, Modern, Posmodern, Saintifik, Hermeneutik, Kritis, Evaluatif, dan Integratif. Yogyakarta: Writing Revolution.

Nigrum Lia Novita. (2011). Pembinaan Anaka Yatim Dan Dhuafa Di Panti Asuhan Yatim Dan Dhuafa AL-Hakim (Sinar Melati 2) Dusun Padasan Kecamatan Pakem Kabupaten Sleman. Universitas Negeri Yokyakarta.

Naszir dkk. (2009). Teori-teori Sosiologi. Bandung: Refika Medika.

Ritzer, George (2012) Teori Sosiologi, Bantul : Kreasi Wacana.

Sugiyono. (2018). Metode Penelitian pendidikan (pendekatan kuantitatif, Kualitatif, dan R\&D). Bandung: Alfabeta.

Soekanto Soerjono. (2010). Sosiologi Suatu Pengantar. PT Raja Grafindo Persada. Jakarta: Rajawali Pers.

Tim Penyusun. (2019). Panduan Penulisan Proposal dan Skripsi. Makassar: Program Studi Pendidikan Sosiologi Fakultas Keguruan dan Ilmu Pendidikan Universitas Muhammadiyah Makassar.

Tim Penyusun. (2018). Buku Pedoman Penulisan Skripsi (Khusus Bagi Mahasiswa Bidang Kajian Penelitian Sosial Budaya). Makassar: Program Studi Pendidikan Sosiologi Fakultas Keguruan dan Ilmu Pendidikan Universitas Muhammadiyah Makassar.

Wahyudin, Din, dkk.( 2007). Pengantar Pendidikan, Jakarta: universitas terbuka. 